\title{
Thermal Conductivity of Magnesium Alloys in the Temperature Range from $-125^{\circ} \mathrm{C}$ to $400^{\circ} \mathrm{C}$
}

\author{
Sanghyun Lee • Hye Jeong Ham • \\ Su Yong Kwon • Sok Won Kim • \\ Chang Min Suh
}

Received: 22 December 2010 / Accepted: 16 December 2011 / Published online: 6 January 2012

(C) The Author(s) 2012. This article is published with open access at Springerlink.com

\begin{abstract}
Magnesium alloys have been widely used in recent years as lightweight structural materials in the manufacturing of automobiles, airplanes, and portable computers. Magnesium alloys have extremely low density (as low as $1738 \mathrm{~kg} \cdot \mathrm{m}^{-3}$ ) and high rigidity, which makes them suitable for such applications. In this study, the thermal conductivity of two different magnesium alloys made by twin-roll casting was investigated using the laser-flash technique and differential scanning calorimetry for thermal diffusivity and specific heat capacity measurements, respectively. The thermal diffusivity of the magnesium alloys, AZ31 and AZ61, was measured over the temperature range from $-125^{\circ} \mathrm{C}$ to $400{ }^{\circ} \mathrm{C}$. The alloys AZ31 and AZ61 are composed of magnesium, aluminum, and zinc. The thermal conductivity gradually increased with temperature. The densities of AZ31 and AZ61 were $1754 \mathrm{~kg} \cdot \mathrm{m}^{-3}$ and $1777 \mathrm{~kg} \cdot \mathrm{m}^{-3}$, respectively. The thermal conductivity of AZ31 was about $25 \%$ higher than that of AZ61, and this is attributed to the amount of precipitation.
\end{abstract}

Keywords AZ31 - AZ61 · Low temperature · Magnesium alloy · Thermal conductivity

\footnotetext{
S. Lee $(\varangle) \cdot$ S. Y. Kwon

Division of Physical Metrology, Korea Research Institute of Standards and Science, 267 Gajeong-Ro, Yuseong-Gu, Daejeon 305-340, Republic of Korea

e-mail: leesh@kriss.re.kr

\section{H. J. Ham · C. M. Suh}

Department of Mechanical Engineering, Kyungpook National University, Daegu 702-701, Republic of Korea

S. W. Kim

Department of Physics, University of Ulsan, Ulsan 680-749, Republic of Korea
} 


\section{Introduction}

Magnesium alloys have a low density, $1738 \mathrm{~kg} \cdot \mathrm{m}^{-3}$, and a high specific stiffness and are used as lightweight structural materials [1]. Their vibration and shock absorption properties are good, along with their excellent electrical, thermal conductivity, high temperature fatigue, and impact properties. As their densities are lower than that of aluminum $\left(2698 \mathrm{~kg} \cdot \mathrm{m}^{-3}\right)$, lightweight structures (parts) of popular vehicles, aircraft, transportation equipment, and general machinery are fabricated from magnesium alloys $[2,3]$. In recent years, devices such as mobile phones and portable laptops have parts made from magnesium alloys to reduce the weight, and as a result, manufacturing research and development in this area are actively ongoing [4]. AZ-series alloys are essentially alloys that include aluminum and zinc, with a magnesium base. AZ31, specifically, is an alloy of 3 mass $\% \mathrm{Al}$ and 1 mass\% $\mathrm{Zn}$, whereas AZ61 is an alloy composed of 6 mass $\% \mathrm{Al}$ and 1 mass $\% \mathrm{Zn}$. AZ91, with added Mn was developed and used for strengthening corrosion resistance [5].

Recently, notebooks require high thermal performance for higher speeds and increased heat dissipation. Such thermal performance is also essential for maintaining an enhanced cooling environment for lightweight parts in automobiles and personal computers. Information about the thermophysical properties of magnesium alloys such as the specific heat capacity and thermal conductivity are relatively scarce. Thus, this article describes a thermal conductivity analysis of magnesium-based alloys of aluminum and zinc, by calculating the thermal conductivity through measurements of the specific heat capacity, thermal diffusivity, and density between $-125^{\circ} \mathrm{C}$ and $400{ }^{\circ} \mathrm{C}$.

\section{Experimental}

Magnesium alloys were made by the twin-roll die casting (TRC) method (POSCO, Korea, AZ31 and AZ61), with magnesium-based compositions of 3 mass $\% \mathrm{Al}$ and 1 mass $\% \mathrm{Zn}$ for AZ31 and 6 mass $\% \mathrm{Al}$ and 1 mass $\% \mathrm{Zn}$ for AZ61. Three alloy specimens were made for each of the two composition types to be used for measurements of the specific heat capacity and thermal diffusivity. The thermal diffusivity was measured with the laser-flash method (Netzsch LFA 457) between $-125^{\circ} \mathrm{C}$ and $400^{\circ} \mathrm{C}$ with a Nd:YAG laser and a liquid-nitrogen-cooled MCT infrared detector. The laser pulse width is $0.33 \mathrm{~ms}$ to $0.5 \mathrm{~ms}$ and the maximum power is $15 \mathrm{~J}$. The environment for the measurements consisted of gaseous helium from $-125^{\circ} \mathrm{C}$ to room temperature, in contrast to an environment in the vacuum state from room temperature to $400{ }^{\circ} \mathrm{C}$. The temperature at the back of the specimen was measured by an mercurycadmium-telluride (MCT) infrared sensor. The dimensions of the specimens were each $10 \mathrm{~mm}$ in diameter and $2 \mathrm{~mm}$ in thickness. They were coated with graphite on both sides to allow homogenous absorption of laser energy. Four measurements for the thermal diffusivity were taken at each temperature, and then the mean was used. Standard deviations of the measurements were $<1 \%$. The calculation of the thermal diffusivity used the analysis of Cape and Lehman [6], while the laser pulse-width correction followed the method of Azumi [7]. The specific heat capacity was measured with a differential scanning calorimeter (Perkin Elmer Pyris 1, Netzsch DSC 404C), 
and the environment consisting of gaseous argon at a flow rate of $50 \mathrm{~mL} \cdot \mathrm{min}^{-1}$ was employed in the DSC measurements. A heating rate of $10 \mathrm{~K} \cdot \mathrm{min}^{-1}$ was applied using SRM-720(NIST synthetic sapphire) as the standard reference material with a stepwisescanning method. The density was measured by the Archimedes method. Finally, the thermal conductivity $\left(\lambda: \mathrm{W} \cdot \mathrm{m}^{-1} \cdot \mathrm{K}^{-1}\right)$ was calculated from the measured specific heat capacity $\left(c_{p}: \mathrm{J} \cdot \mathrm{g}^{-1} \cdot \mathrm{K}^{-1}\right)$, the thermal diffusivity $\left(\alpha: \mathrm{m}^{2} \cdot \mathrm{s}^{-1}\right)$ and the density $\left(\rho: \mathrm{kg} \cdot \mathrm{m}^{-3}\right)$, using the equation,

$$
\lambda=\rho \mathrm{c}_{p} \alpha
$$

We used an optical microscope and scanning electron microscope (SEM) to observe the structure. Each specimen was ground and corroded by Kalling's agent for usage. SEM-EDS (energy dispersion spectroscopy) was used to evaluate the chemical composition.

\section{Results and Discussion}

Magnesium alloys, used in this study, were manufactured by the TRC method. Table 1 presents the chemical compositions of such magnesium alloys. The chemical compositions of the magnesium alloys included aluminum with a range between 3 mass $\%$ and 6 mass $\%$.

Figure 1 is an optical micrograph of AZ31and AZ61. The grain size of AZ31 is (10 to 30$) \mu \mathrm{m}$, compared to AZ61 with a grain size of (10 to 20) $\mu \mathrm{m}$. Similar to El-Morsy [8], our observation on AZ61 confirmed the existence of $\mathrm{Al}_{12} \mathrm{Mg}_{17}$ extracts around the grain boundary of $\alpha$-Mg. Figure 2 shows similar phenomena in SEM micrographs of AZ31 and AZ61. The precipitation of $\mathrm{Al}_{12} \mathrm{Mg}_{17}$ in the solid solution of magnesium is known to affect the thermal conductivity.

The densities of the magnesium alloys, AZ31 and AZ61, were measured to be $1754 \mathrm{~kg} \cdot \mathrm{m}^{-3}$ and $1777 \mathrm{~kg} \cdot \mathrm{m}^{-3}$, respectively. Due to the considerably reduced densities compared to aluminum and steel, they have been widely used for reducing the density of the alloys. A recent decrease in the cost of magnesium made it almost as affordable as aluminum [2], and has stimulated further growth in the usage of its alloys.

Figure 3 shows the mean of four thermal-diffusivity measurements for each specimen of AZ31 and AZ61, using the laser flash method. The thermal diffusivity of AZ-series alloys had $<1 \%$ standard deviation for each measurement, and the combined uncertainty $(k=2)$ of measurement was about $3 \%$. The three measurement results agree well within each alloy, as the standard deviation of the thermal diffusivity is $<2 \%$. The thermal diffusivity of AZ31 shows a sharp increase with temperature

Table 1 Chemical composition of AZ31 and AZ61 magnesium alloys (mass\%)

\begin{tabular}{llll}
\hline & Al & Zn & $\mathrm{Mg}$ \\
\hline AZ31 & 3.0 & 1.0 & Balance \\
AZ61 & 6.2 & 0.9 & Balance \\
\hline
\end{tabular}




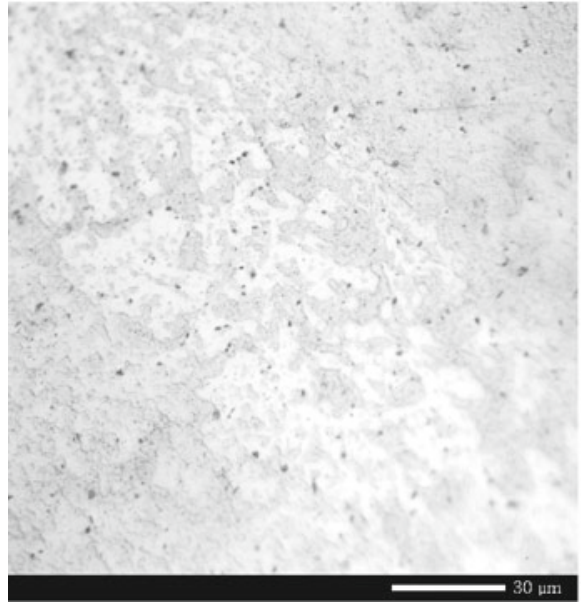

(a) AZ31

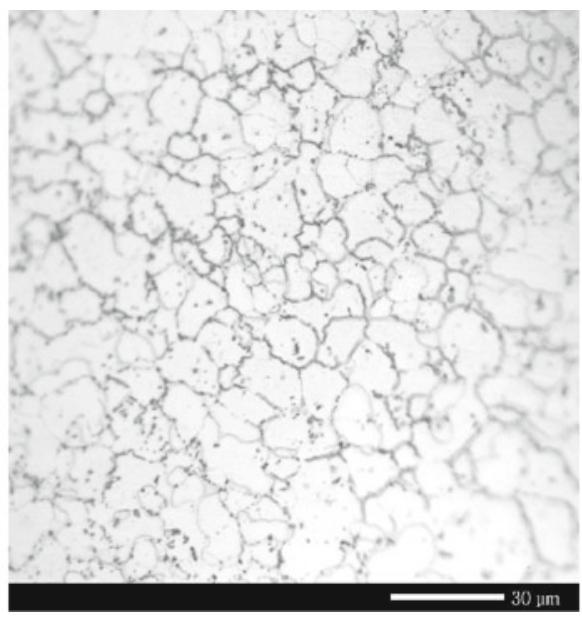

(b) AZ61

Fig. 1 Optical micrographs of (a) AZ31 and (b) AZ61 magnesium alloys
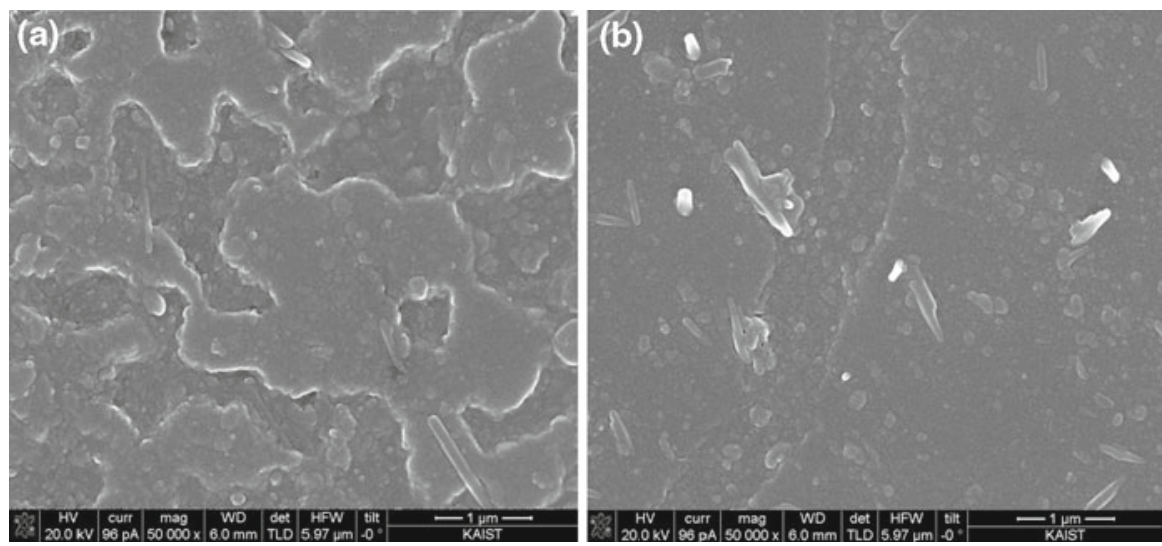

Fig. 2 SEM micrographs of (a) AZ31 and (b) AZ61 magnesium alloys

at room temperature and below, but a steady increase with temperature at $100{ }^{\circ} \mathrm{C}$ or above. The thermal diffusivity of AZ61 displays the same trend, except it is 25\% lower than that of AZ31 at room temperature. According to Yamasaki and Kawamura [9], AZ61 tends to have a lower thermal conductivity due to the solid solution, given a higher level of aluminum than for AZ31. The measurements of Rudajevova and Lukac [10] for the thermal conductivity of aluminum/magnesium (AM) alloys also show that the thermal conductivity decreases as the amount of aluminum increases. This result is considered to be the effect of $\mathrm{Al}_{12} \mathrm{Mg}_{17}$ precipitation.

Figure 4 shows the results of specific heat capacity measurements at $50 \mathrm{~K}$ increments. The specific heat capacities of AZ31 and AZ61 are not significantly different due to the relatively small difference in aluminum quantities. According to Emsley 


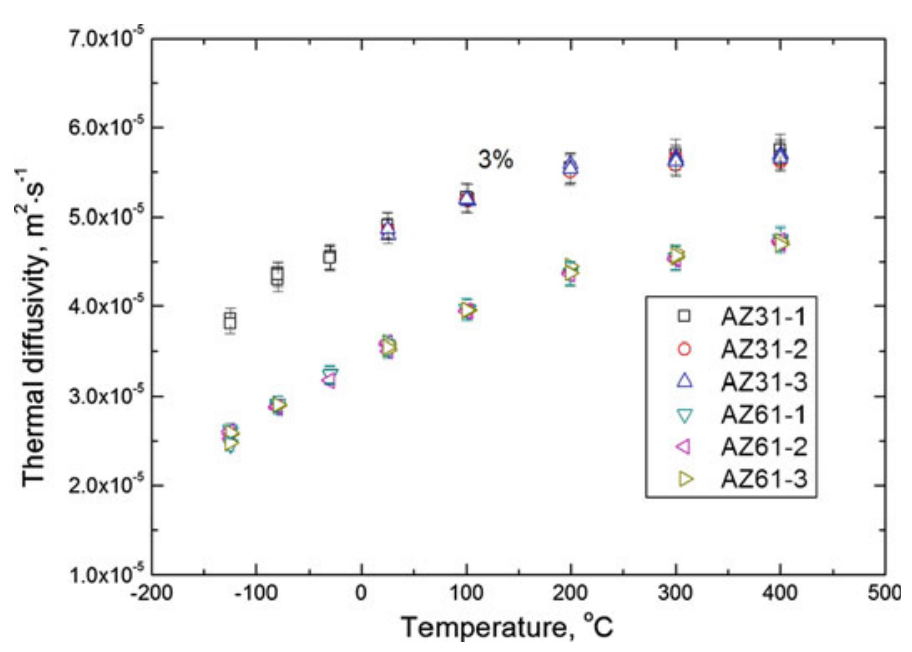

Fig. 3 Measured thermal diffusivity of AZ31 and AZ61

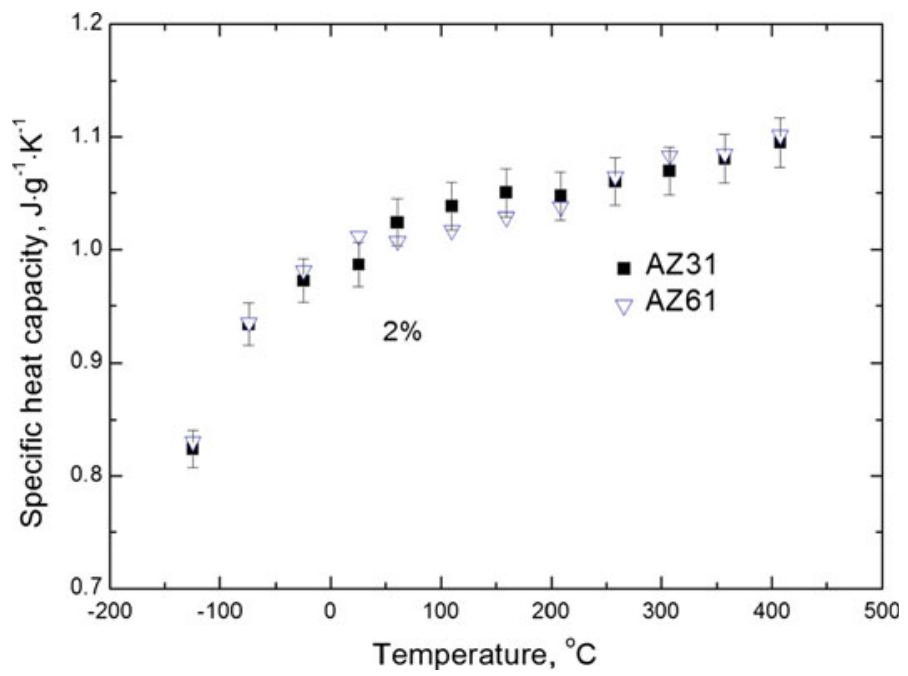

Fig. 4 Measured specific heat capacity of AZ31 and AZ61

[1], the specific heat capacities of magnesium and aluminum at room temperature, $1.0241 \mathrm{~J} \cdot \mathrm{g}^{-1} \cdot \mathrm{K}^{-1}$ and $0.9025 \mathrm{~J} \cdot \mathrm{g}^{-1} \cdot \mathrm{K}^{-1}$, respectively, show very little difference. Therefore, changes in the specific heat capacities of magnesium alloys for differing proportions of aluminum are insignificant. The fitted values of the specific heat capacity are displayed in Table 2 and used in the calculations of the thermal conductivity.

In Fig. 5, AZ61 shows a thermal-conductivity range of $(45.3$ to 83.5$) \mathrm{W} \cdot \mathrm{m}^{-1} \cdot \mathrm{K}^{-1}$, which is more than (25 to 50) \% higher than that of AZ31. The major components of the AZ magnesium alloys are magnesium, aluminum, and zinc, each with a thermal conductivity at room temperature of $156 \mathrm{~W} \cdot \mathrm{m}^{-1} \cdot \mathrm{K}^{-1}, 237 \mathrm{~W} \cdot \mathrm{m}^{-1} \cdot \mathrm{K}^{-1}$, 


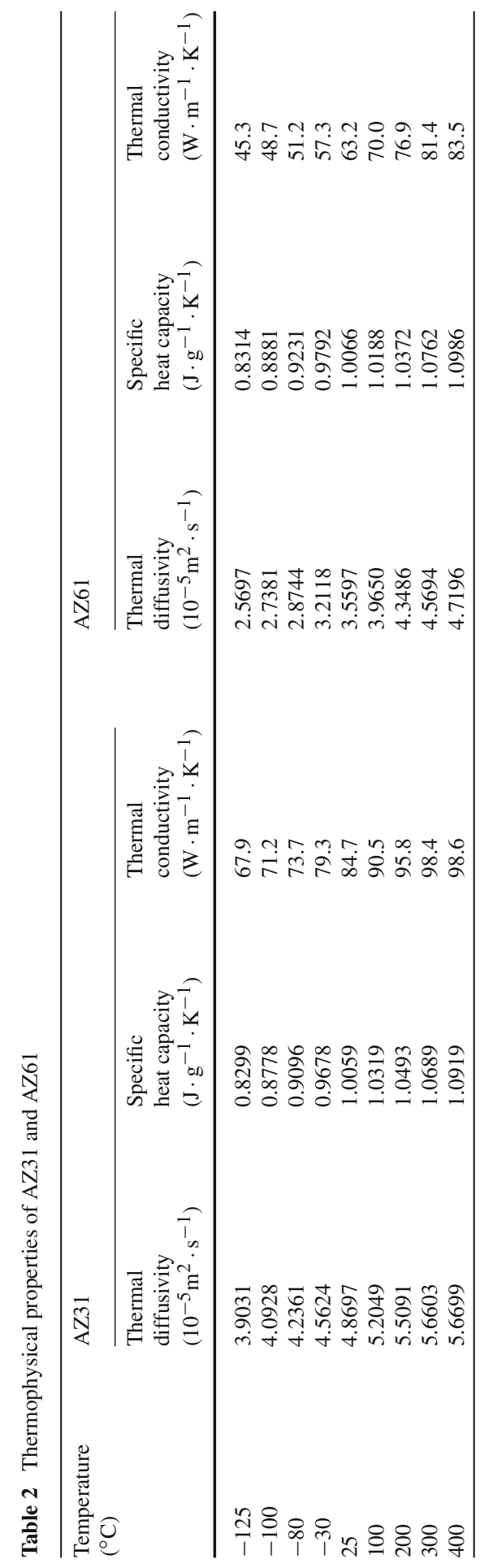




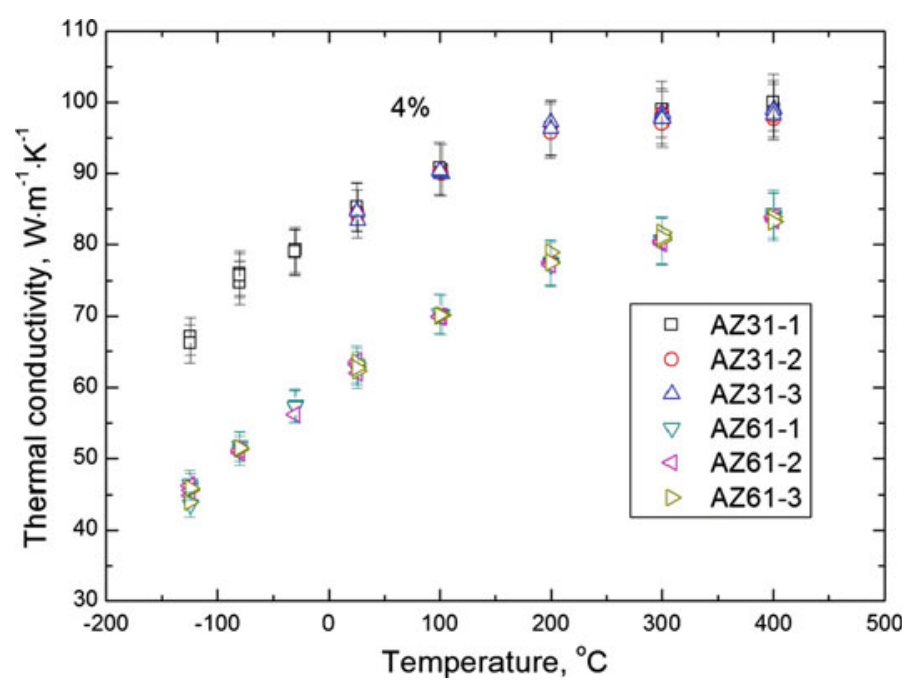

Fig. 5 Calculated thermal conductivity of AZ31 and AZ61

and $116 \mathrm{~W} \cdot \mathrm{m}^{-1} \cdot \mathrm{K}^{-1}$, respectively [1]. The thermal conductivity of AZ31 at room temperature is observed to be $84.7 \mathrm{~W} \cdot \mathrm{m}^{-1} \cdot \mathrm{K}^{-1}$, nearly $25 \%$ higher than the value of $63.2 \mathrm{~W} \cdot \mathrm{m}^{-1} \cdot \mathrm{K}^{-1}$ for $\mathrm{AZ61}$, as $\mathrm{Al}_{12} \mathrm{Mg}_{17}$ precipitations from the aluminum solid solution have a significant effect on the thermal conductivity. AZ31 has a thermal conductivity of $84.7 \mathrm{~W} \cdot \mathrm{m}^{-1} \cdot \mathrm{K}^{-1}$ at room temperature, which is similar when compared to $88.7 \mathrm{~W} \cdot \mathrm{m}^{-1} \cdot \mathrm{K}^{-1}(\mathrm{Mg}: 97.9$ mass $\%, \mathrm{Al}: 2.1 \mathrm{mass} \%)$ for a comparable alloy described in the TPRC data book [11]. Also at $100^{\circ} \mathrm{C}$, the thermal conductivity of AZ61 is $70.0 \mathrm{~W} \cdot \mathrm{m}^{-1} \cdot \mathrm{K}^{-1}$, which is close to $75.3 \mathrm{~W} \cdot \mathrm{m}^{-1} \cdot \mathrm{K}^{-1}$ for a similar compound (Mg: 94 mass\%, $\mathrm{Al}: 6$ mass\%) at TPRC.

\section{Conclusions}

This study provides measurements of the specific heat capacity, thermal diffusivity, and density for two types of magnesium alloys; these results are used to calculate the thermal conductivity. In conclusion, the thermal conductivity showed a tendency to increase with temperature. The thermal conductivity at $-125^{\circ} \mathrm{C}$ was $20 \%$ less for AZ31 and $28 \%$ less for AZ61 compared to that at room temperature. Also, the thermal conductivity of magnesium alloys decreases with an increase in the percentage of aluminum, due to the interference of a precipitation in a solid solution. The thermophysical property data from this study can be useful in the thermal design for automobiles and notebook applications.

Open Access This article is distributed under the terms of the Creative Commons Attribution Noncommercial License which permits any noncommercial use, distribution, and reproduction in any medium, provided the original author(s) and source are credited. 


\section{References}

1. J. Emsley, The Elements, 2nd edn. (Oxford University Press, London, 1990), pp. 110-111

2. M.K. Kulekci, Int. J. Adv. Technol. 39, 851 (2008)

3. S.S. Park, W.J. Park, C.H. Kim, B.S. You, N.J. Kim, JOM 61, 14 (2009)

4. H.K. Tsai, C.C. Liao, F.K Chen, J. Mater. Process Technol. 201, 247 (2008)

5. A. Rudajevova, J. Keihn, K.U. Kainer, B.L. Mordike, P. Lukac, Scr. Mater 40, 57 (1999)

6. J.A. Cape, G.W. Lehman, J. Appl. Phys. 34, 1909 (1963)

7. T. Azumi, Y. Takahashi, Rev. Sci. Instrum. 32, 1411 (1981)

8. A. El-Morsy, A. Ismail, M. Waly, Mater. Sci. Eng. A 486, 528 (2008)

9. M. Yamasaki, Y. Kawamura, Scr. Mater 60, 264 (2009)

10. A. Rudajevova, P. Lukac, Mater. Sci. Eng. A 397, 16 (2005)

11. Y.S. Touloukian, R.W. Powell, C.Y. Ho, P.G. Klemens, Thermophysical Properties of Matter (TPRC Data Series), vol. 1 (IFI/Plenum, New York, 1970), pp. 658-660 